\title{
Position statement on EUS-guided ablation of pancreatic cystic neoplasms from an international expert panel
}

\section{(ㄷ)(1)}

Authors

Anthony Yuen-Bun Teoh ${ }^{1}$, Dong Wan Seo ${ }^{2}$, William Brugge ${ }^{3}$, John Dewitt ${ }^{4}$, Pradermchai Kongkam ${ }^{5}$, Enqiang Linghu ${ }^{6}$, Matthew T. Moyer ${ }^{7}$, Ji Kon Ryu ${ }^{8}$, Khek Yu Ho ${ }^{9}$

Institutions

1 Department of Surgery, Prince of Wales Hospital, The Chinese University of Hong Kong, Hong Kong

2 Department of Gastroenterology, Asan Medical Centre, Seoul, Korea

3 Pancreas Biliary Center, Gastrointestinal Unit, Massachusetts General Hospital, Boston, Massachusetts, United States

4 Division of Gastroenterology, Department of Medicine, Indiana University Hospital, Indianapolis, Indiana, United States

5 Pancreas Research Unit and Gastrointestinal Endoscopy Excellent Center, Department of Medicine, Faculty of Medicine, Chulalongkorn University and King Chulalongkorn Memorial Hospital, Bangkok, Thailand

6 Department of Gastroenterology, Chinese PLA General Hospital, Beijing, China

7 Division of GI-Hepatology and Penn State University Cancer Institute, Penn State Hershey Medical Center, Hershey, Pennsylvania, United States

8 Department of Internal Medicine, Seoul National University College of Medicine, Seoul, Korea

9 Department of Medicine, National University of Singapore, Singapore

submitted 30.1.2019

accepted after revision 11.4 .2019

\section{Bibliography}

DOI https://doi.org/10.1055/a-0959-5870 |

Endoscopy International Open 2019; 07: E1064-E1077

(c) Georg Thieme Verlag KG Stuttgart · New York eISSN 2196-9736

Corresponding author

Prof. Anthony Yuen Bun Teoh, Department of Surgery, The Chinese University of Hong Kong, Prince of Wales Hospital, Shatin, New Territories, Hong Kong SAR, China

Fax: +852-2637-7974

anthonyteoh@surgery.cuhk.edu.hk

\section{ABSTRACT}

Background and aim Recently, several guidelines with divergent recommendations on management of pancreatic cystic neoplasm have been published but the role of endoscopic ultrasound (EUS)-guided pancreatic cyst ablation has not been thoroughly addressed. The aim of the current paper is to explore the issues surrounding EUS-guided pancreatic cyst ablation by generating a list of clinical questions and providing answers based on best scientific evidence available.

Methods An expert panel in EUS-guided pancreatic cyst ablation was recruited from members of the Asian EUS group and an international expert panel. A list of clinical questions was created and each question allocated to one member to generate a statement in response. The statements were then discussed in three Internet conference meetings between October 2016 and October 2017. The statements were changed until consensus was obtained. Afterwards, the complete set of statements was sent to all the panelist to vote on strength of the statements, classification of the statement sand grading of the evidence.

Results Twenty-three statements on EUS-guided drainage of pancreatic cyst ablation were formulated. The statements addressed indications for the procedures, technical aspects, pre-procedure and post-procedure management, management of complications, and competency and training in the procedures.

Conclusion The current set of statements on EUS-guided pancreatic cyst ablation are the first to be published by any endoscopic society. Clinicians interested in developing the technique should reference these statements and future studies should address the key issues raised in the document. 


\section{Introduction}

Management of pancreatic cystic neoplasms (PCN) remains controversial. The fundamental aim is to prevent mortality associated with the established malignant progression of PCN [1]. However, knowledge of specific cyst histology and grade using current imaging and cyst sampling techniques is often difficult without surgical resection. As a result, specific management strategies based on known or suspected cyst pathology can be challenging.

Recently, guidelines from the American Gastroenterology Association (AGA) and the European study group were published [2,3]. In conjunction with the Fukuoka guidelines, formulation of these guidelines was largely based on observational studies with wide variations in the quality of evidence [1]. Furthermore, the role of endoscopic ultrasound (EUS)-guided pancreatic cyst ablation was either not discussed or discussed only briefly. Hence, the aim of the current paper was to explore issues surrounding EUS-guided pancreatic cyst ablation by generating a list of clinical questions and providing answers based on best scientific evidence available.

\section{Methods}

An expert panel in EUS-guided pancreatic cyst ablation was recruited from members of the Asian EUS group and an international expert panel. The Asian EUS group comprises experts in surgery, interventional EUS, interventional radiology, and oncology from 18 Asian countries with a primary focus on promotion of education and research in EUS. To formulate the list of document statements, it was understood that many issues on EUS-guided ablation are controversial, supported by limited evidence and it might be difficult to achieve group consensus. Hence, other methods used to establish guidelines with strong recommendations (e.g. GRADE and US Preventive Services Taskforce recommendations) may be inappropriate to apply to the current document $[4,5]$. Rather, the group sought to generate a list of statements for clinicians to reference when adopting techniques in EUS-guided cyst ablation. The response to each statement, however, was based on the best scientific evidence available.

A modified Delphi process was employed to establish statements in this position paper. A planning group (TAY, SDW) created a list of clinical questions based on indications for the procedure, procedural preparations, procedural considerations, potential adverse events ( $\mathrm{AE}$ ) and management, and competency and training. Each clinical question was allocated to one member and the member was responsible for generating a statement in response to the question. Each statement was based on a systematic literature search using pubmed, Medline and Embase from January 1, 1992 to April 30, 2017. Articles were selected using mesh headings and text words including: pancreatic cyst, pancreatic cyst ablation, EUS-guided cyst ablation, pancreatic mucinous neoplasm, and intraductal papillary mucinous neoplasm. Only English language studies were included and prospective and/or comparative studies were preferred. Reference lists from eligible trials were also checked to locate missing publications. Where the article fulfilled the selection criterion, a copy of the full manuscript was obtained. Full manuscripts were then reviewed and a final decision was made about the inclusion. Studies published only in abstract form, conference abstracts, symposium proceedings, and case reports were not eligible for inclusion. Any disagreements were resolved by consensus.

After the statements were generated, the panelists met via three Internet conference meetings between October 2016 and October 2017 to discuss each of the clinical scenarios and statements. The statements were changed until consensus was obtained. Afterwards, the complete set of statements was sent to all the panelist to vote on strength of each statement, classification of the statement, and grading of the evidence. The strength of a statement was classified as recommended or not recommended.

Each statement was classified as: A-There is good evidence to support the statement; $\mathrm{B}$-There is fair evidence to support the statement; $\mathrm{C}$ - There is poor evidence to support the statement but recommendation was made on other grounds; DThere is fair evidence to refute the statement; or E-There is good evidence to refute the statement. Quality of evidence was rated using GRADE ratings [6]. It was rated high when we were very confident that the true effect lies close to that of the estimate of the effect. It was rated moderate if we were moderately confident in the effect estimate. It was rate low if our confidence estimate was limited and very low if we had very little confidence in the effect estimate.

\section{Statements: Indications for the procedure (॰ Table 1)}

\section{Clinical question 1}

When should we perform pancreatic cyst ablation?

\section{Statement}

In patients who are not surgical candidates or refuse surgery with a reasonable life expectancy and suffering from either:

- Unilocular or oligolocular cyst with a presumed or confirmed diagnosis of a mucinous pancreatic cyst.

- Enlarging pancreatic cysts with a diameter of $>2 \mathrm{~cm}$ or pancreatic cysts with diameter of $>3 \mathrm{~cm}$ in size.

The aim of surgical resection of PCN is to prevent mortality from malignant progression of a PCN. However, estimated risk of malignancy quoted by the various guidelines differs significantly ( $\triangleright$ Table 2) [1-3]. The goal of EUS-guided pancreatic cyst ablation is to completely destroy the neoplastic lining of the cystic tumor to eliminate the lesion and/or decrease its likelihood for progression into malignancy. Thus, the procedure is most suitable for selected patients with unilocular cysts over $2 \mathrm{~cm}$ without definite pancreatic mass or signs of malignancy and who refuse surgery or hold an excessive risk for perioperative AEs associated with major pancreatic surgery. There are currently no randomized studies comparing pancreatic cyst ablation versus no treatment or pancreatic cyst ablation versus 
- Table 1 Position statements on EUS-guided pancreatic cyst ablation.

\begin{tabular}{|c|c|c|c|c|}
\hline No. & Question & Statement & $\begin{array}{l}\text { Classifi- } \\
\text { cation } \\
\text { of state- } \\
\text { ment }\end{array}$ & $\begin{array}{l}\text { Quality of } \\
\text { evidence }\end{array}$ \\
\hline \multicolumn{5}{|c|}{ Indications for the procedure } \\
\hline 1 & $\begin{array}{l}\text { When should we perform } \\
\text { pancreatic cyst ablation? }\end{array}$ & $\begin{array}{l}\text { In patients who are not surgical candidates or refuse surgery with a rea- } \\
\text { sonable life expectancy and suffering from either: } \\
\text { - Unilocular or oligolocular cyst with a presumed or confirmed diagnosis } \\
\text { of a mucinous pancreatic cyst. } \\
\text { - Enlarging pancreatic cysts with a diameter of }>2 \mathrm{~cm} \text { or pancreatic cysts } \\
\text { with diameter of }>3 \mathrm{~cm} \text { in size. }\end{array}$ & B & Moderate \\
\hline 2 & $\begin{array}{l}\text { What size and configura- } \\
\text { tion of the pancreatic cyst } \\
\text { respond best to ablation? }\end{array}$ & $\begin{array}{l}\text { Pancreatic cysts with } 6 \text { or less locules and measuring } 2 \text { to } 6 \mathrm{~cm} \text { in diameter } \\
\text { respond best to ablation. }\end{array}$ & B & Moderate \\
\hline 3 & $\begin{array}{l}\text { What are the contraindi- } \\
\text { cations to the procedure? }\end{array}$ & $\begin{array}{l}\text { Absolute contraindications } \\
\text { - Pregnancy, irreversible coagulopathy, signs of pancreatic malignancy, } \\
\text { active pancreatitis or pancreatic necrosis or a short life expectancy. } \\
\text { Relative contraindications } \\
\text { " Cyst with enhancing mural nodules, cyst with no or low malignant po- } \\
\text { tential, dilated main pancreatic }>5 \text { mm in size, clear open communica- } \\
\text { tion of the cyst with the main pancreatic duct, more than } 6 \text { locules } \\
\text { comprising the cyst, thick walls, thick septations, MPD stricture with } \\
\text { pancreatic tail atrophy, significant solid components within the cyst, } \\
\text { and a past medical history of acute pancreatitis. }\end{array}$ & B & Moderate \\
\hline 4 & $\begin{array}{l}\text { What level of certainty of } \\
\text { diagnosis is required be- } \\
\text { fore the procedure? }\end{array}$ & $\begin{array}{l}\text { The treating physician should be reasonably certain that the cyst is not a } \\
\text { benign asymptomatic pancreatic cyst with no or low malignant potential. } \\
\text { The degree of pre-procedure testing required to diagnose other types of } \\
\text { pancreatic cysts will vary among physicians to ensure a proper diagnosis for } \\
\text { patient counselling and the planned treatment for the patient. }\end{array}$ & B & Moderate \\
\hline \multicolumn{5}{|c|}{ Procedural preparations } \\
\hline 5 & $\begin{array}{l}\text { What investigational } \\
\text { modalities are required } \\
\text { before EUS cyst ablation is } \\
\text { performed? }\end{array}$ & $\begin{array}{l}\text { We recommend all patients to be evaluated with contrast enhanced com- } \\
\text { puted tomography (pancreatic protocol) or enhanced magnetic resonance } \\
\text { imaging with cholangiopancreatography (MRCP) and/or endoscopic ultra- } \\
\text { sonography (EUS-FNA) before ablation. Anatomic and morphological fea- } \\
\text { tures of the pancreatic cysts should be evaluated and EUS-FNA may be } \\
\text { performed for biochemical and cytological examination to aid in diagnosis } \\
\text { of the cyst. }\end{array}$ & B & Moderate \\
\hline 6 & $\begin{array}{l}\text { Are prophylactic antibio- } \\
\text { tics required? }\end{array}$ & $\begin{array}{l}\text { Prophylactic antibiotics (fluoroquinolones or beta-lactamase) are recom- } \\
\text { mended to prevent post-procedural infection. }\end{array}$ & C & Moderate \\
\hline 7 & $\begin{array}{l}\text { How long does antibiotics } \\
\text { need to be continued if } \\
\text { given? }\end{array}$ & Antibiotics if given, should be continued for 3 to 5 days. & C & Moderate \\
\hline \multicolumn{5}{|c|}{ Procedural considerations } \\
\hline 8 & $\begin{array}{l}\text { What size of the needle } \\
\text { should be used? }\end{array}$ & A $19 G$ or $22 \mathrm{G}$ needle should be used for aspiration and injection. & B & Moderate \\
\hline 9 & $\begin{array}{l}\text { Should the fluid be aspira- } \\
\text { ted completely or not be- } \\
\text { fore ablation? }\end{array}$ & $\begin{array}{l}\text { We suggest leaving a small rim of fluid around the tip of the needle within } \\
\text { the cyst (after the initial aspiration) before the ablation process. }\end{array}$ & C & Very low \\
\hline 10 & $\begin{array}{l}\text { What should be done if the } \\
\text { cyst fluid is too viscous to } \\
\text { be aspirated out during } \\
\text { EUS-FNA? }\end{array}$ & $\begin{array}{l}\text { We suggest using a 19-gauge needle under high suction pressure to aspi- } \\
\text { rate the viscous fluid. The viscosity of the cyst can then be lowered by in- } \\
\text { jection of equal volumes of normal saline or alcohol that were aspirated } \\
\text { out. The process is repeated to allow the majority of the cyst fluid to be as- } \\
\text { pirated for ablation. }\end{array}$ & C & Very low \\
\hline 11 & $\begin{array}{l}\text { What are the available } \\
\text { agents for the procedure? }\end{array}$ & $\begin{array}{l}\text { Use of ethanol lavage only, ethanol lavage followed by the infusion of pa- } \\
\text { clitaxel, an alcohol-free saline lavage followed by an admixture of paclitax- } \\
\text { el-gemcitabine, and use of lauromacrogol have been reported in clinical } \\
\text { trials. }\end{array}$ & A & High \\
\hline
\end{tabular}


- Table 1 (Continuation)

\begin{tabular}{|c|c|c|c|c|}
\hline No. & Question & Statement & $\begin{array}{l}\text { Classifi- } \\
\text { cation } \\
\text { of state- } \\
\text { ment }\end{array}$ & $\begin{array}{l}\text { Quality of } \\
\text { evidence }\end{array}$ \\
\hline 12 & $\begin{array}{l}\text { Is ethanol required for ef- } \\
\text { fective pancreatic cyst ab- } \\
\text { lation? }\end{array}$ & $\begin{array}{l}\text { Ethanol is the traditional agent used for ablation, however, two recent trials } \\
\text { have shown that ethanol is not required for effective cyst ablation when a } \\
\text { chemotherapeutic agent appropriate for cyst ablation is used. }\end{array}$ & A & High \\
\hline 13 & $\begin{array}{l}\text { What is the difference be- } \\
\text { tween aspiration, lavage } \\
\text { and retention? Are there } \\
\text { any differences between } \\
\text { the practices? }\end{array}$ & $\begin{array}{l}\text { Aspiration refers to the removal of cyst fluid by the aspiration needle. La- } \\
\text { vage is the repetitive aspiration and reinjection of the lavage agent for } 3 \text { to } \\
5 \text { minutes. Retention is to retain the injected ethanol for } 20 \text { minutes to } 40 \\
\text { minutes while rotating patient position, particularly for large cyst. After a } \\
\text { retention period, the injected ethanol is aspirated completely. Infusion re- } \\
\text { fers to replacement of the cyst content with an ablation agent (eg pacli- } \\
\text { taxel or gemcitabine-paclitaxel) which is then left in place. }\end{array}$ & C & Low \\
\hline \multicolumn{5}{|c|}{ Outcomes of EUS-guided pancreatic cyst ablation } \\
\hline 14 & $\begin{array}{l}\text { How should a response to } \\
\text { therapy be defined as after } \\
\text { the procedure? }\end{array}$ & $\begin{array}{l}\text { Completeness of response is defined by the amount of reduction in volume } \\
\text { of the cyst }(4 / 3 \pi r 3) \text { where } r \text { is the cyst radius as measured by the primary } \\
\text { imaging modality at initial and } 6 \text {-month follow-up. } \\
\text { Complete response is defined as } 95 \% \text { or greater reduction in volume of the } \\
\text { cyst. } \\
\text { Partial response is then a } 75 \% \text { to } 95 \% \text { reduction in volume of the cyst and } \\
\text { non-response would be defined as }<75 \% \text { reduction in volume of the cyst. }\end{array}$ & C & Very low \\
\hline 15 & $\begin{array}{l}\text { What are the results of } \\
\text { pancreatic cyst ablation? }\end{array}$ & $\begin{array}{l}\text { Complete cyst resolution with ethanol alone occurs in about } 30 \% \text { of treated } \\
\text { cysts. The addition of paclitaxel infusion following ethanol lavage increases } \\
\text { complete resolution to } 60 \%-79 \% \text {. }\end{array}$ & A & High \\
\hline 16 & $\begin{array}{l}\text { What are the effects of } \\
\text { ablation on cyst epithe- } \\
\text { lium? }\end{array}$ & $\begin{array}{l}\text { Surgery is rarely performed after cyst ablation. However, reported histo- } \\
\text { logic epithelial ablation rates after endoscopic therapy of pancreatic cysts } \\
\text { ranges from } 0 \% \text { to } 100 \% \text { but are generally between } 50 \% \text { and } 100 \% \text {. }\end{array}$ & $C$ & Low \\
\hline 17 & $\begin{array}{l}\text { What are the cytological } \\
\text { and genetic changes after } \\
\text { the procedure? }\end{array}$ & $\begin{array}{l}\text { Data are limited data suggesting that genetic changes revert to normal } \\
\text { after cyst ablation. }\end{array}$ & $C$ & Low \\
\hline \multicolumn{5}{|c|}{ Follow-up and monitoring } \\
\hline 18 & $\begin{array}{l}\text { How should these patients } \\
\text { be followed up and moni- } \\
\text { tored? }\end{array}$ & $\begin{array}{l}\text { Patients treated with pancreatic cyst ablation and followed non-operative- } \\
\text { ly should undergo cross-sectional imaging at } 6 \text {-month intervals for the first } \\
\text { year and then annually until no longer warranted due to patient age and } \\
\text { medical conditions. This is to monitor for recurrences after ablation and } \\
\text { possible incomplete histologic ablation following treatment. }\end{array}$ & B & Moderate \\
\hline \multicolumn{5}{|c|}{ Potential AEs and management } \\
\hline 19 & $\begin{array}{l}\text { What are the potential ad- } \\
\text { verse events of the proce- } \\
\text { dure? }\end{array}$ & $\begin{array}{l}\text { It is assumed that EUS-guided pancreatic cyst ablation carries the baseline } \\
\text { risks of standard EUS-FNA procedures, which are considered safe and rarely } \\
\text { associated with adverse events. Specific AEs associated with the ablation } \\
\text { itself include self-limiting abdominal pain, acute pancreatitis, and VTE. }\end{array}$ & A & Moderate \\
\hline 20 & $\begin{array}{l}\text { Are there systemic effects } \\
\text { from the chemotherapeu- } \\
\text { tic agent during and after } \\
\text { the procedure? }\end{array}$ & $\begin{array}{l}\text { Paclitaxel in doses used for pancreatic cyst ablation has been shown to be } \\
\text { safe when injected into pancreatic cysts without identifiable blood levels of } \\
\text { the agent post-procedure. }\end{array}$ & B & Moderate \\
\hline \multicolumn{5}{|c|}{ Competency and training } \\
\hline 21 & $\begin{array}{l}\text { Who should learn the pro- } \\
\text { cedure? }\end{array}$ & $\begin{array}{l}\text { EUS-guided cyst ablation is a technically challenging procedure. Physicians } \\
\text { undertaking this procedure are expected to have completed an accredited, } \\
\text { standardized training program in interventional endoscopy, as outlined by } \\
\text { the appropriate national society governing that center. They should be } \\
\text { competent in EUS-FNA and also EUS interventional procedures. }\end{array}$ & $\mathrm{C}$ & Low \\
\hline
\end{tabular}


- Table 1 (Continuation)

\begin{tabular}{|c|c|c|c|c|}
\hline No. & Question & Statement & $\begin{array}{l}\text { Classifi- } \\
\text { cation } \\
\text { of state- } \\
\text { ment }\end{array}$ & $\begin{array}{l}\text { Quality of } \\
\text { evidence }\end{array}$ \\
\hline 22 & $\begin{array}{l}\text { How should training of the } \\
\text { procedure be undertaken? }\end{array}$ & $\begin{array}{l}\text { Only physicians who have completed training in EUS and EUS-FNA with ap- } \\
\text { propriate credentialing should perform pancreatic cyst ablation. Perform- } \\
\text { ance of five procedures under supervision is recommended to gain appro- } \\
\text { priate experience for an endoscopist fluent in EUS to gain competency. }\end{array}$ & C & Very low \\
\hline 23 & $\begin{array}{l}\text { Which centers should pro- } \\
\text { vide training of the proce- } \\
\text { dure? }\end{array}$ & $\begin{array}{l}\text { Training should be obtained in a high-volume training center. The center } \\
\text { should possess a multi-disciplinary team including the expert endosono- } \\
\text { grapher, surgical oncologist and radiologist for discussion of each patient's } \\
\text { condition and treatment strategy. }\end{array}$ & B & Very low \\
\hline
\end{tabular}

- Table 2 Risk stratification of pancreatic cyst in different guidelines.

\begin{tabular}{|c|c|c|c|}
\hline & Fukouka guidelines [1] & European guidelines [2] & AGA guidelines [3] \\
\hline $\begin{array}{l}\text { High-risk features (Fukouka) } \\
\text { Or } \\
\text { Absolute indication for surgery } \\
\text { (European) } \\
\text { Or } \\
\text { Predictive of malignancy (AGA) }\end{array}$ & $\begin{array}{l}\text { Mucinous cystic neoplasms (MCN) } \\
\text { or IPMN with either: } \\
\text { Obstructive jaundice with PCN in } \\
\text { head of pancreas } \\
\text { MPD dilation } \geq 1 \mathrm{~cm} \\
\text { Enhancing solid nodules } \\
\text { Positive cytology }\end{array}$ & $\begin{array}{l}\text { Positive cytology for malignancy } \\
\text { of HGD } \\
\text { Solid mass } \\
\text { Tumor related obstructive jaun- } \\
\text { dice } \\
\text { Enhancing mural nodules } \\
\text { ( } \geq 5 \mathrm{~mm} \text { ) } \\
\text { MPD dilation } \geq 10 \mathrm{~mm}\end{array}$ & $\begin{array}{l}\text { Cyst }>3 \mathrm{~cm} \\
\text { Solid component associated with } \\
\text { the cyst and } \\
\text { Dilated MPD (no size criteria) }\end{array}$ \\
\hline $\begin{array}{l}\text { Worrisome features (Fukouka) } \\
\text { Or } \\
\text { Relative indication for surgery } \\
\text { (European) }\end{array}$ & $\begin{array}{l}\text { Cyst diameter } \geq 3 \mathrm{~cm} \\
\text { Thickened enhanced cyst walls } \\
\text { Non-enhanced mural nodules } \\
\text { MPD size of } 5 \text { to } 9 \mathrm{~mm} \\
\text { Abrupt change in the MPD caliber } \\
\text { with distal pancreatic atrophy } \\
\text { Lymphadenopathy }\end{array}$ & $\begin{array}{l}\text { Cystic growth rate } \geq 5 \mathrm{~mm} / \text { year } \\
\text { Increased level of serum CA } 19.9 \\
(>37 \mathrm{U} / \mathrm{mL}) \\
\text { Symptoms } \\
\text { Enhancing mural nodules } \\
(<5 \mathrm{~mm}) \\
\text { And/or a cyst diameter } \\
\geq 40 \mathrm{~mm} \text { are features of increased } \\
\text { risk of malignancy }\end{array}$ & \\
\hline
\end{tabular}

surgery. Hence, there is no clear evidence that the postulated survival benefits outweigh the risks associated with the procedure and institutions performing the procedure should do so under a research protocol.

\section{Clinical question 2}

What size and configuration of the pancreatic cyst respond best to ablation?

\section{Statement}

Pancreatic cysts with 6 or less locules and measuring 2 to $6 \mathrm{~cm}$ in diameter respond best to ablation.

In the literature, EUS-guided pancreatic cyst ablations were performed in cysts 10 to $68 \mathrm{~mm}$ in diameter [7-18]. Cysts on the smaller size of that range respond better to ablation [12]. Cysts less than $35 \mathrm{~mm}$ in diameter were shown to predict com- plete response in one study [13]. Risk of developing AEs did not seem to relate to cyst diameter. Pancreatic cysts that are either unilocular or oligolocular (defined as $2-6$ locules within a cyst) with thin walls and thin septations are technically more favorable for cyst ablation with fewer locules being more favorable.

\section{Clinical question 3}

What are the contraindications to the procedure?

\section{Statement}

\section{Absolute contraindications}

- Pregnancy, irreversible coagulopathy, signs of pancreatic malignancy, active pancreatitis or pancreatic necrosis or a short life expectancy. 


\section{Relative contraindications}

Cyst with enhancing mural nodules, cyst with no or low malignant potential, dilated main pancreatic $>5 \mathrm{~mm}$ in size, clear open communication of the cyst with the main pancreatic duct, more than 6 locules comprising the cyst, thick walls, thick septations, main pancreatic duct (MPD) stricture with pancreatic tail atrophy, significant solid components within the cyst, and a past medical history of acute pancreatitis.

In published series, EUS-guided pancreatic cyst ablation has a low AE rate [7-13]. However, the procedure should be done only in appropriately selected cases and avoided in patients with contraindications. General absolute contraindications are similar to other endoscopic procedures including patients with coagulopathy and pregnancy. Specific contraindications to the procedure include overt signs of malignancy and a short life expectancy as the anticipated benefit for the procedure is limited and unlikely to impact survival in this group of patients. In addition, pancreatic necrosis is also an absolute contraindication due to risk of developing pancreatitis after cyst ablation.

Relative contraindications to the procedure include cyst with enhancing mural nodules, cyst with no or low malignant potential, dilated main pancreatic $>5 \mathrm{~mm}$ in size, clear open communication of the cyst with the MPD, more than six locules comprising the cyst, thick walls, thick septations, significant solid components within the cyst, and a past medical history of acute pancreatitis. Concern exists about entrance of the injectate into the main pancreatic duct during treatment of a cyst with clear communication with the MPD, which may result in pancreatitis. However, branched type intraductal papillary mucinous neoplasms (IPMNs) with visible connection to the MPD were recruited in two studies provided the cyst was not directly adjacent to the MPD and there was no visible communication with the MPD during aspiration (volume in syringe larger than anticipated volume) and injection (fluid exiting the cyst) $[10,11]$. The rate of pancreatitis was $2.4 \%$ in this study and this is within the range of AEs rates reported in other studies. Presence of enhancing mural nodules, thickened walls, thick septations, MPD stricture with pancreatic tail atrophy, and significant solid components within the cyst maybe signs of frank malignancy. Ablation of these cysts should be considered cautiously only in patients that are not candidates for surgery.

\section{Clinical question 4}

What level of certainty of diagnosis is required before the procedure?

\section{Statement}

The treating physician should be reasonably certain that the cyst is not a benign asymptomatic pancreatic cyst with no or low malignant potential. The degree of pre-procedure testing required to diagnose other types of pancreatic cysts will vary among physicians to ensure proper diagnosis for patient counselling and planned treatment for the patient.

Pre-procedural diagnosis of pancreatic cysts can be made by radiological assessment, interval assessment of lesions, EUS morphology, cystic fluid analysis, cytology, and molecular studies [7 - 13]. In some centers, acquisition of specimens for tumor markers, genetic analysis or cytopathological studies are not essential for making pre-procedural diagnosis and EUS-guided ablation is performed in the same session with EUS-FNA [9]. Other centers will require a diagnosis be made before any treatment is provided to the pancreatic cyst $[8,10,12]$. Clinicians embarking on the procedure should adhere to institutional guidelines and counsel patients accordingly.

\section{Statements: Procedural preparations}

\section{Clinical question 5}

What investigational modalities are required before EUS cyst ablation is performed?

\section{Statement}

We recommend that all patients be evaluated with contrast-enhanced computed tomography (pancreatic protocol) or enhanced magnetic resonance imaging with cholangiopancreatography (MRCP) and/or endoscopic ultrasonography (endoscopic ultrasound-guided fine-needle aspiration [EUS-FNA]) before ablation. Anatomic and morphological features of the pancreatic cysts should be evaluated and EUS-FNA may be performed for biochemical and cytological examination to aid in diagnosis of the cyst.

In all of the guidelines, magnetic resonance imaging (MRI) is the preferred method for initial evaluation of the PCN [1-3]. $\mathrm{MRI} / \mathrm{MRCP}$ is more sensitive than $\mathrm{CT}$ in identifying any connection between the PCN and pancreatic ductal system and presence of mural nodules or internal septations [19-22]. EUS should be used as an adjunct to assess for presence of highrisk features that would be better treated by resection. FNA should be considered to obtain cytology and fluid for biochemical analysis. Cytology has a high specificity but a low sensitivity. Hence, negative cytology does not exclude the diagnosis of mucinous neoplasm [23-28]. Use of cyst fluid analysis may help differentiate between mucinous and non-mucinous cyst. A CEA level $\geq 192 \mathrm{ng} / \mathrm{mL}$ is sensitive in $52 \%$ to $78 \%$ and specific in $63 \%$ to $91 \%$ of patients $[25,26,29-33]$. In some instances, the exact type of cyst may still remain uncertain. Newer adjuncts like needle-based confocal laser endomicroscopy (NCLE), through-the-needle biopsy or direct observation with fiber optic probe may help further improve diagnostic accuracy for pancreatic cysts but are not endorsed in recent guidelines. Use of NCLE could provide virtual histopathologic assessment and has a reported diagnostic accuracy of between $71 \%$ and $93 \%$ [34-38]. Initial concerns about increased risk of pancreatitis were not repeated in recent studies $[34,36,39]$. The technique may be a useful adjunctive to aid diagnosis in situations where cyst fluid analysis was inconclusive. Use of through-the-needle biopsy forceps or direct observation under fiber optic probe will need further evaluation as outcomes are less well reported [39-41]. 
Clinical question 6

Are prophylactic antibiotics required?

\section{Statement}

Prophylactic antibiotics (fluoroquinolones or beta-lactamase) are recommended to prevent post-procedural infection.

\section{Clinical question 7}

How long do antibiotics need to be continued if given?

\section{Statement}

Antibiotics if given, should be continued for 3 to 5 days.

It is common practice to give prophylactic antibiotics before and after EUS-FNA of pancreatic cysts; however, the practice is supported by limited evidence [42-46]. Most studies use a single dose of prophylactic intravenous (IV) antibiotics that is continued for 3 to 5 days orally. One retrospective study of 519 patients assessed the need for antibiotics for EUS-FNA of pancreatic cysts. The authors found that incidence of infective complications was very low with or without antibiotics (0.58\%). Two studies have examined use of a single prophylactic dose of IV antibiotics and found no infectious complications with the practice $[44,45]$. There is no information on which antibiotics should be used and at what dosage they should be given. Provision of antibiotics should follow standards established by national guidelines.

\section{Statements: Procedural considerations}

Clinical question 8

What size needle should be used?

\section{Statement}

A $19 G$ or $22 \mathrm{G}$ needle should be used for aspiration and injection.

There are no studies comparing efficacy of $19 \mathrm{G}$ and 22G needles in pancreatic cyst ablation. In general, larger-diameter needles allow easier aspiration of mucinous material, which is often viscous, from within the cyst. However, 19G needles are stiffer and may be difficult to use for lesions located in the pancreatic head. Use of $19 \mathrm{G}$ nitinol needles may overcome this problem [47]. An additional problem with 19G needles is that the ablation fluid may be easier to leak out from the cyst and some authors prefer the use of 22G needles [48]. In general, $25 \mathrm{G}$ needles are not recommended as aspiration of viscous cyst fluid is difficult and debris inside the cyst could block the needle.

\section{Clinical question 9}

Should the fluid be aspirated completely or not before ablation?

\section{Statement}

We suggest leaving a small rim of fluid around the tip of the needle within the cyst (after the initial aspiration) before the ablation process.

There are no studies assessing this technique. However, to prevent the tip of the needle damaging surrounding pancreatic tissue or leading to extravasation of alcohol, the needle tip should remain in the exact center of a cyst during the lavage and/or infusion process. Thus, it is suggested not to completely aspirate out all the fluid within the cyst and leave a small rim of fluid around the tip of the needle.

\section{Clinical question 10}

What should be done if the cyst fluid is too viscous to be aspirated out during EUS-FNA?

\section{Statement}

We suggest using a 19-gauge needle under high suction pressure to aspirate the viscous fluid. The viscosity of the cyst then be lowered by injection of equal volumes of normal saline or alcohol that were aspirated out. The process is repeated to allow aspiration of the majority of the cyst fluid for ablation.

The ablative effects of agents used for pancreatic cyst ablation depend on direct contact with the epithelium. The agents cause membrane lysis, protein denaturation, and vascular occlusion of the epithelium [49]. To maximize the ablative effects of the agents, the majority of the cyst fluid should be aspirated out so the most of the cyst wall can be in contact with the agent. In cysts where the fluid is too viscous for aspiration, several strategies could be adopted. First, a 19-gauge needle should be used to puncture the cyst. The Hagen-Poiseuille Law indicates that flow rate is proportional to $\mathrm{R} 4$, where $\mathrm{R}$ is the radius of a cylinder. In a 19-gauge catheter, the needle diameter is $0.912 \mathrm{~mm}$ and the flow rate is four times faster than the 22 gauge catheter, with a diameter of $0.644 \mathrm{~mm}$. Thus, a larger needle could significantly increase the flow rate of viscous fluid. Second, a 20-mL syringe should be used for aspiration. According to Boyle's Law, P1V1=P2V2, the volume in a closed system is inversely proportional to pressure, such that an increase in volume decreases pressure and increases vacuum. Thus, when the plunger of a syringe is pulled in the closed system, volume is created. Hence, larger syringes can effectively create more volume and thus more vacuum. Third, an endoscopist attempting to aspirate a viscous fluid collection should use the shortest extension tubing possible and use braided tubing, which will resist collapsing, to maximize vacuum dynamics. The length of a pipe is inversely proportional to flow rate. Extra tubing introduces more air that must be extracted by the syringe, resulting in diminished vacuum pressure.

Once some viscous fluid is aspirated out from the cyst, the viscosity of the cyst then can be lowered by injection of equal volumes of normal saline or alcohol equal to what was aspirated. The volume of fluid aspirated out may be in increments of $1 \mathrm{~mL}$ or less. The process is repeated until the majority of the cyst fluid can be aspirated out for ablation.

\section{Clinical question 11}

What are the available agents for the procedure?

\section{Statement}

Use of ethanol lavage only, ethanol lavage followed by infusion of paclitaxel, an alcohol-free saline lavage followed by an ad- 
mixture of paclitaxel-gemcitabine, and use of lauromacrogol have been reported in clinical trials.

\section{Clinical question 12}

Is ethanol required for effective pancreatic cyst ablation?

\section{Statement}

Ethanol is the agent traditionally used for ablation, however, two recent trials have shown that ethanol is not required for effective cyst ablation when a chemotherapeutic agent appropriate for cyst ablation is used.

\section{Ethanol}

To date, 10 published studies have investigated the safety and efficacy of EUS-guided ethanol lavage, only two of which used a randomized design ( $\triangleright$ Table 3 ). Clinical usefulness of ethanolonly lavage for pancreatic cyst ablation is controversial, as rates of complete cyst resolution following treatment range from $9 \%$ to $35 \%$ in published prospective studies. The concentration of ethanol used in these studies has ranged from $80 \%$ to $100 \%$. Some of the most concerning findings surrounding efficacy of EUS-guided ethanol lavage came from a 2016 study by from Gomez and colleagues, which demonstrated very low rates of efficacy withethanol lavage [50]. Complete resolution was observed in only $9 \%$ of patients. The authors concluded that ethanol lavage alone may not be a promising method for prevention of malignancy in pancreatic cysts. In addition, $80 \%$ of all conducted studies have reported at least one $A E[8-12,15-17$, 50]. The most frequent $A E$ is abdominal pain, where at least one case has been reported in $70 \%$ of the published studies and reported incidence is $2 \%$ to $20 \%$ [ $9-11,15-17,50]$. The principle major $A E$ in trials has been acute pancreatitis, where at least one case has been documented in $60 \%$ of studies and incidence rates are as high as $10 \%$. These AEs have generally been attributed to the inflammatory nature of ethanol [9-12, $15,50]$.

\section{Ethanol lavage followed by infusion of paclitaxel}

Oh et al. reported on use of paclitaxel for pancreatic cyst ablation after ethanol lavage and this method has been confirmed in other studies $[7,9,15,16,50]$. Paclitaxel is a chemotherapeutic agent that arrests cellular microtubule assembly and interferes with $\mathrm{G}_{2}$ mitotic phase cell replication. The addition of infusing and leaving $6 \mathrm{mg} / \mathrm{mL}$ paclitaxel in the cyst has been shown in separate trials to raise complete ablation rates to $50 \%$ to $79 \%$. Of note, certain preparations of paclitaxel are viscous and require $50 \%$ dilution with saline to facilitate infusion of the agent through an EUS-FNA needle. Consequently, most of the published studies have reported use of paclitaxel at a $3 \mathrm{mg} / \mathrm{mL}$ concentration. Thus, use of ethanol lavage followed by infusion of paclitaxel has gained significant favor as the current standard of care for this procedure. However, the reason for the increased rate of cyst resolution may be due to a synergistic effect between the two agents at the level of the cyst wall $[7,15]$.

\section{Ethanol-free infusion of paclitaxel-gemcitabine}

Recently, a randomized, prospective pilot study has been published comparing a completely ethanol-free chemoablation approach with conventional ethanol lavage [12]. After either ethanol or normal saline injection, both arms then received chemotherapeutic infusion to the pancreatic cyst $(19 \mathrm{mg} / \mathrm{mL}$ gemcitabine $+3 \mathrm{mg} / \mathrm{mL}$ paclitaxel). While limited by small numbers, this study demonstrated no statistically significant difference in complete ablation rates between the ethanol and alcohol-free arms, suggesting that ethanol is not required for effective pancreatic cyst ablation when a chemotherapy cocktail specifically tailored for pancreatic neoplasia is used. Importantly, the ethanol ablation group incurred major complications at rates similar to previous studies while patients in the alcoholfree arm developed no AEs. These results were then confirmed in the larger, prospective, randomized CHARM trial by the same group [8]. Complete ablation was observed in $67 \%$ of the patients in the alcohol-free group as compared to $61 \%$ in the ethanol control group (non-inferior). Importantly, serious AEs occurred in $6 \%$ of patients in the control group vs none of the patients in the alcohol-free group. Minor AEs occurred in $22 \%$ of patients in the control group and none of the patients in the alcohol-free group $(P=0.01)$. The overall rate of complete ablation was $64 \%$. These studies demonstrate that ethanol is not required for effective EUS-guided pancreatic cyst ablation.

\section{Lauromacrogol}

Lauromacrogol (also known as polidocanol) is a new agent reported for pancreatic cyst ablation [51]. Lauromacrogol is a local anesthetic and sclerosant. It is approved by the US Food and Drug Administration as a sclerosant for spider veins and varicose veins [52]. Other reported uses of lauromacrogol include treatment of esophageal and gastric varices, tendinopathy, and ablation of renal cysts. In a recent study, lauromacrogol was used for EUS-guided ablation of pancreatic cysts. Twentynine patients underwent 36 treatments. Mild pancreatitis occurred in two patients and fever in one, giving an AE rate of approximately $10 \%$. The complete resolution rate was $37.9 \%$, which appears to be similar to the lower rates of effective ablation seen with ethanol ablation.

Based on the above studies, the preferred approach for EUSguided chemoablation appears to be either saline lavage followed by infusion of paclitaxel-gemcitabine or, in some centers, ethanol lavage followed by infusion of paclitaxel. However, results from randomized studies comparing agents are scarce.

\section{Clinical question 13}

What is the difference between aspiration, lavage and retention? Are there any differences between the practices?

\section{Statement}

Aspiration refers to removal of cyst fluid with the aspiration needle. Lavage is repetitive aspiration and reinjection of the lavage agent for 3 to 5 minutes. Retention is to retain the injected ethanol for 20 to 40 minutes while rotating patient position, particularly for a large cyst. After a retention period, the injected ethanol is aspirated completely. Infusion refers to replace- 
- Table 3 Summary of studies for EUS-guided ethanol ablation with or without paclitaxel and gemcitabine.

\begin{tabular}{|c|c|c|c|c|}
\hline Author, year & Study Type & Conditions (no. patients) & $\begin{array}{l}\text { Complete (CR) or par- } \\
\text { tial resolution (PR) }\end{array}$ & Clinically significant $\mathrm{AEs}^{1}$ \\
\hline \multicolumn{5}{|c|}{ Studies that used ЕTOH for ablation } \\
\hline Gan et al. 2005 [14] & $\begin{array}{l}\text { Prospective } \\
\text { (pilot) }\end{array}$ & $5-80 \%$ ETOH (25) & $\begin{array}{l}35 \% \mathrm{CR} \\
7 \% \mathrm{PR}\end{array}$ & $0 \%$ \\
\hline Dewitt et al. 2009 [10] & Prospective (RCT) & $\begin{array}{l}80 \% \text { ETOH }(25) \\
\text { SALINE (17) }\end{array}$ & $\begin{array}{l}33 \% \mathrm{CR}^{2} \\
0 \% \mathrm{CR}\end{array}$ & $\begin{array}{l}24 \% \text { ( } 4 \% \text { pancreatitis, } 20 \% \text { ab- } \\
\text { dominal pain) } \\
12 \% \text { (abdominal pain) }\end{array}$ \\
\hline Dimaio et al. 2011 [17] & Retrospective & $80 \% \mathrm{ETOH}(13)$ & $38 \% C R$ & $8 \%$ (abdominal pain) \\
\hline Gomez et al. 2016 [50] & Prospective (pilot) & $80 \%$ ETOH (23) & $\begin{array}{l}9 \% \mathrm{CR} \\
44 \% \mathrm{PR}\end{array}$ & $\begin{array}{l}8 \% \text { ( } 4 \% \text { pancreatitis, } 4 \% \text { abdomi- } \\
\text { nal pain) }\end{array}$ \\
\hline \multicolumn{5}{|c|}{ Studies that used ETOH and paclitaxel for ablation } \\
\hline Oh et al. 2008 [15] & Prospective & $88-99 \%$ ETOH + paclitaxel (14) & $\begin{array}{l}79 \% \text { CR } \\
14 \% \mathrm{PR}\end{array}$ & $\begin{array}{l}21 \% \text { ( } 7 \% \text { pancreatitis, } 14 \% \text { ab- } \\
\text { dominal pain) }\end{array}$ \\
\hline Oh et al. 2009 [16] & Prospective & $99 \% \mathrm{ETOH}+$ paclitaxel (10) & $\begin{array}{l}60 \% \mathrm{CR} \\
20 \% \mathrm{PR}\end{array}$ & $10 \%$ (abdominal pain) \\
\hline Oh et al. 2011 [9] & Prospective & $99 \% \mathrm{ETOH}+$ paclitaxel (47) & $\begin{array}{l}62 \% \mathrm{CR} \\
13 \% \mathrm{PR}\end{array}$ & $\begin{array}{l}4 \% \text { ( } 2 \% \text { pancreatitis, } 2 \% \text { abdomi- } \\
\text { nal pain) }\end{array}$ \\
\hline Dewitt et al. 2014 [11] & Prospective & $100 \%$ ETOH + paclitaxel (22) & $\begin{array}{l}50 \% C R \\
25 \% P R\end{array}$ & $\begin{array}{l}23 \%(10 \% \text { pancreatitis, } 13 \% \text { ab- } \\
\text { dominal pain) }\end{array}$ \\
\hline \multicolumn{5}{|c|}{ Studies that used ETOH, paclitaxel and gemcitabine for ablation } \\
\hline Moyer et al. 2016 [12] & Prospective (pilot) & $\begin{array}{l}80 \% \text { ETOH then paclitaxel + } \\
\text { gemcitabine (4) } \\
\text { Saline then paclitaxel + } \\
\text { gemcitabine (6) }\end{array}$ & $\begin{array}{l}75 \% \text { CR } \\
67 \% \text { CR }\end{array}$ & $\begin{array}{l}20 \% \text { (pancreatitis) } \\
0 \%\end{array}$ \\
\hline Moyer et al. 2017 [8] & Prospective RCT & $\begin{array}{l}80 \% \text { ETOH then paclitaxel + } \\
\text { gemcitabine ( } 18) \\
\text { Saline then paclitaxel+ } \\
\text { gemcitabine ( } 21 \text { ) }\end{array}$ & $\begin{array}{l}61 \% C R \\
67 \% C R\end{array}$ & $\begin{array}{l}\text { Serious AE } 6 \% \text {, minor AE } 22 \% \\
\text { Serious AE 0\%, minor AE 0\% }\end{array}$ \\
\hline \multicolumn{5}{|c|}{$\begin{array}{l}\text { ETOH, ethanol alcohol; CR, complete response; PR, partial response; AE, adverse event; RCT, randomized clinical trial. } \\
{ }^{1} \text { The overall \% of AEs described here represents the sum of AEs reported in corresponding studies (in parentheses), focusing on the two most common AEs reported: } \\
\text { abdominal pain and pancreatitis. However, based on reported study results, it cannot be determined whether AE categories overlapped (e. g., whether a patient } \\
\text { documented with pancreatitis also counted toward the reported AE rate for abdominal pain). Other less commonly reported AEs include intracystic bleeding ( } 26 \text { ), } \\
\text { splenic vein obliteration (21), hyperamylasemia (20), gastric wall cyst (27), and peritonitis ( } 27 \text { ) } \\
2 \text { In this study, } 23 \% \text { of patients undergoing saline lavage and a second ETOH lavage had CR, 33\% undergoing ETOH lavage twice had CR, and } 75 \% \text { undergoing a single } \\
\text { ETOH lavage had CR[ 3] The published results [12] are from a smaller sample (N=10; ETOH arm: } 75 \% \text { CR, } 20 \% \text { AEs; ETOH-free arm: } 67 \% \text { CR, } 0 \% \text { AEs), but the final } \\
\text { randomized controledl trial is listed at the bottom (8). }\end{array}$} \\
\hline
\end{tabular}

ment of the cyst content with an ablation agent (eg paclitaxel or gemcitabine-paclitaxel), which is then left in place.

The technique of EUS-guided pancreatic cyst ablation first involves complete aspiration of the cyst with a 19G or 22G needle to near collapse. The amount of cyst fluid aspirated should be recorded and the same amount of lavage or ablative agent reinjected. Then, either lavage or infusion of the ablative agent can be carried out [7-18]. There are no data comparing the different approaches. The type of practice depends on the institutional protocol. Lavage is generally preferred for unilocular or oligolocular cysts without complex internal structures. For thick-walled cysts and cysts with complex internal structures, retention therapy can give longer contact time with the lavage agent and more chance of spread of the agent into individual locules.

\section{Statements: Outcomes of EUS-guided pancreatic cyst ablation}

\section{Clinical question 14}

How should a response to therapy be defined after the procedure?

\section{Statement}

Completeness of response is defined by the amount of reduction in volume of the cyst $(4 / 3 \pi r 3)$ where $r$ is the cyst radius as measured by the primary imaging modality at initial and 6 month follow-up.

Complete response is defined as $95 \%$ or greater reduction in volume of the cyst. Partial response is then a $75 \%$ to $95 \%$ re- 
duction in volume of the cyst and non-response would be defined as $<75 \%$ reduction in the volume of the cyst.

Changes in appearance of an ablated pancreatic cyst are measured by alterations in both size and morphology. Alterations in size before and after ablation are typically evaluated by cross-sectional imaging performed pretreatment and then at 6 and 12 months following the last endoscopic ablation [911]. Under ideal circumstances, the same study and imaging protocol (pancreas protocol multidetector CT or $3 \mathrm{~T} \mathrm{MRI/}$ MRCP) should be used for each study.

Measurement of volume changes can be done using either two-dimensional $\left(4 / 3 \pi r^{3}\right.$ - where $r$ is the largest cyst radius or $4 / 3 \pi a b c-$ where a,b, $c$ are the 3 dimensions of an elliptical model) or three-dimensional $(d 1 \times d 2 \times d 3 / 2$, where $d$ is the diameter of the cyst in each dimension) measurements. Complete response to ablation has been defined as a reduction in cyst volume by at least $95 \%$. Partial response and non-response to treatment have been defined as a reduction in $75 \%$ to $95 \%$ and $0 \%$ to $74 \%$, respectively [ $9-11]$.

EUS may also be used to measure size and morphology changes in these patients. After ablation, a single-center study showed that sonographic changes include increase in cyst wall thickness in $68 \%$, decreased number of septations in $24 \%$, and loss of a mural nodule in $21 \%$ [53]. The increase in cyst wall thickness likely reflects denuding of the epithelium and chronic inflammatory changes that have been reported in patients undergoing surgery after pancreatic cyst ablation $[9,10]$.

\section{Clinical question 15}

What are the results of pancreatic cyst ablation?

\section{Statement}

Complete cyst resolution with ethanol alone occurs in about $30 \%$ of treated cysts. The addition of paclitaxel infusion following ethanol lavage increases complete resolution to $60 \%$ to $79 \%$.

As mentioned above, rates of complete cyst resolution with ethanol lavage alone are between $9 \%$ and $35 \%[10,14]$. The addition of paclitaxel at a concentration of 3 to $6 \mathrm{mg} / \mathrm{mL}$, infused and left in the cyst following ethanol lavage, increases complete and partial resolution to $50 \%$ to $79 \%$ and $19.6 \%$ to $25 \%$, respectively $[7,9,11,15,16,26,50,53]$. Of interest, one small study also assessed efficacy of two ablations versus a single ablation [17]. Two ablations resulted in significantly larger reduction in surface area of the cysts (Baseline: $5734 \pm 6846 \mathrm{~mm}^{2}$; one EUS-EL session, $4906 \pm 9240 \mathrm{~mm}^{2}[P=0.52]$; and two EUSEL sessions, $\left.2311 \pm 4093 \mathrm{~mm}^{2}[P=0.008]\right)$ and higher rates of complete ablation ( $35 \%$ vs $0 \%, P=0.02$ ). Thus, repeated ablation may be a viable option to increase efficacy of cyst ablation.

\section{Clinical question 16}

What are the effects of ablation on cyst epithelium?

\section{Statement}

Surgery is rarely performed after cyst ablation. However, reported histologic epithelial ablation rates after endoscopic therapy of pancreatic cysts range from $0 \%$ to $100 \%$ but are generally between $50 \%$ and $100 \%$.

Most patients undergoing cyst ablation do not proceed to surgery since a complete or partial response is seen in the majority and ablation is generally reserved for patients at high risk for surgery. However, histologic examination of patients proceeding to surgery following cyst ablation have shown variable epithelial ablation rates of $0 \%$ to $100 \%$ and associated chronic inflammation in the treated cyst wall $[9-11,14]$. Epithelial cell loss may occur in untreated pancreatic cysts, therefore use of denudation alone as a marker of successful ablation is questionable [50].

\section{Clinical question 17}

What are the cytological and genetic changes after the procedure?

\section{Statement}

Data are limited suggesting that genetic changes revert to normal after cyst ablation.

Aspiration of pancreatic cyst fluid several months after ablation reveals cytology findings similar to those found after sampling a pseudocyst. Namely, there is an increased number or initial appearance of macrophages and inflammatory cells [53]. Cyst fluid may decrease as well. Post-ablation cyst fluid DNA was increased in quantity, decreased in quality, and demonstrated loss of mutations such as KRAS. These findings likely reflect epithelial cell destruction and turnover following from ablation $[11,26]$.

\section{Statements: Follow-up and monitoring}

\section{Clinical question 18}

How should these patients be followed up and monitored?

\section{Statement}

Patients treated with pancreatic cyst ablation and followed non-operatively should undergo cross-sectional imaging at 6month intervals for the first year and then annually until no longer warranted due to patient age and medical conditions. This is to monitor for recurrences after ablation and possible incomplete histologic ablation following treatment.

Image-defined volume changes after ablation represent the technique most commonly used to assess response. However, size change may not reflect cyst epithelial cell loss and therefore represents only an indirect method to assess response. Other methods to detect changes such as pathology, morphology, and genetics have been investigated as well and may provide supplemental information to guide therapy.

Most patients with pancreatic cysts treated with endoscopic ablation have a decrease in cyst volume on follow-up imaging. However, despite early studies showing long-term response is possible in all patients, recurrence of the treated cyst may occur in $1.7 \%$ on subsequent imaging $[13,54]$. Furthermore, in- 
complete ablation of epithelium has been documented in patients undergoing surgery after treatment. Therefore, routine follow-up after treatment is recommended. Following ablation, patients should undergo cross sectional imaging in 6 to 12 months after their last ablation to assess response. Patients with an image-defined partial or complete response should undergo cross-sectional imaging annually (preferably with MRI) to assess for recurrence and/or worrisome morphologic changes. If these occur, surgery or retreatment may be considered [13].

\section{Statements: Potential AEs and management}

Clinical question 19

What are the potential AEs of the procedure?

\section{Statement}

It is assumed that EUS-guided pancreatic cyst ablation carries the baseline risks of standard EUS-FNA procedures, which are considered safe and rarely associated with AEs. Specific AEs associated with the ablation itself include self-limiting abdominal pain, acute pancreatitis, and venous thromboembolism (VTE).

AEs associated with standard EUS-FNA are low (0.3-1\%) [55]. The specific AEs of EUS-guided pancreatic cyst ablation are mostly mild and self-limited. Abdominal pain after cyst ablation is the most common AE and is reported in up to $25 \%$ of cases. Cyst infection occurs at a reported rate of $0 \%$ to $9 \%$. Most significantly, iatrogenic acute pancreatitis occurs in $2 \%$ to $10 \%$ of procedures but most are mild and self-limiting [7, 11]. The cause is believed to be secondary to extravasation of ethanol and its markedly inflammatory effects. Other serious AEs felt to be likely due to extravasation of ethanol include VTE in adjacent veins $(0.7 \%)$ and peritonitis $(0-1 \%)$. The safety of EUS-guided ablation may be further improved, with equivalent efficacy, through use of an alcohol-free chemoablation protocol as suggested by two recent randomized prospective trials $[8,12]$.

\section{Clinical question 20}

Are there systemic effects from the chemotherapeutic agent during and after the procedure?

\section{Statement}

Paclitaxel in doses used for pancreatic cyst ablation has been shown to be safe when injected into pancreatic cysts without identifiable blood levels of the agent post-procedure $[8,14$, 16,56]. In addition, systemic paclitaxel doses can be as high as $175 \mathrm{mg} / \mathrm{m}^{2}$ during IV administration for oncologic indications. Because an average person is approximately $1.7 \mathrm{~m}^{2}$, these systemic doses are much higher than that used in pancreatic cyst ablation applications reported to date.

\section{Statements: Competency and training}

Clinical question 21

Who should learn the procedure?

\section{Statement}

EUS-guided cyst ablation is technically challenging. Physicians undertaking this procedure are expected to have completed an accredited, standardized training program in interventional endoscopy, as outlined by the appropriate national society governing that center. They should be competent in EUS-FNA and also EUS interventional procedures.

For example, US endoscopists wishing to perform this procedure should have finished a standardized 1-year interventional endoscopy training program after successfully completing a 3year fellowship in gastroenterology. As such, the endoscopists should have successfully reached the minimum numbers to assess competency for EUS and further specified in the EUS Core Curriculum from the ASGE Training Committee [57, 58].

It is strongly recommended that physicians performing EUSguided tumor ablation do so as part of a high-volume referral center and regularly participate in a multidisciplinary group including radiologists, gastroenterologists, and surgical oncologists to appropriately select patients for this procedure. The interventionist should clearly report the key clinical aspects of the procedure, including cyst type; presence of high-risk features; volume, type, and concentration of ablative agent injected; needle and technique used; as well as pre- and post-ablation EUS findings and follow-up plan [1].

\section{Clinical question 22}

How should training for thCastilloe procedure be undertaken?

\section{Statement}

Only physicians who have completed training in EUS and EUSFNA with appropriate credentialing should perform pancreatic cyst ablation. Performance of five procedures under supervision is recommended to gain appropriate experience for an endoscopist fluent in EUS to gain competency.

Technical training must include observation of the procedure, learning the technique for aspiration, injection, irrigation, lavage, retention, type of needle and injected material, and the ability to adjust and determine appropriate volume of injected material. Endoscopists should also liaise with their local radiologist and pharmacy to seek support for ablative agents used for the procedure. No specific study has focused on the learning curve for EUS-guided pancreatic cyst ablation so far. However, the group agrees that in clinicians competent in techniques of EUS-FNA, competency in the procedure could be obtained with a small number of procedures.

\section{Clinical question 23}

Which centers should provide training for the procedure?

\section{Statement}

Training should be obtained in a high-volume training center. The center should possess a multidisciplinary team including 
an expert endosonographer, surgical oncologist, and radiologist for discussion of each patient's condition and treatment strategy.

Management of pancreatic cysts by EUS-guided ablation is still considered investigational at this time. Diagnosis of these lesions is often difficult and multidisciplinary input is very beneficial. Furthermore, surgical excision is the standard treatment for cysts suspicious for malignancy and excision should be offered to suitable patients. EUS-guided cyst ablation should be reserved for patients who are not candidates for surgery but who have a reasonable life expectancy with cysts that have the characteristics mentioned previously and without signs of overt malignancy. It is hence strongly recommended that the EUSguided pancreatic cyst ablation procedure be performed only in high-volume centers.

In summary, 23 questions were raised, answered as statements, and the recommendations voted on by authors based on quality of evidence. Three statements were voted as recommended with high-grade evidence, 15 were recommended with moderate-grade evidence, and five were recommended with low-/very-low-grade evidence.

\section{Discussion}

EUS-guided interventions are gaining popularity around the world. This set of documents is part of a project commissioned by the Asian EUS group (AEG) aimed at standardizing methods used in various EUS-guided interventional procedures. Guidelines on EUS-guided celiac plexus ablation and drainage of pancreatic fluid collections, bile and pancreatic ducts were previously published [59]. When examining the procedure on EUS-guided pancreatic cyst ablation, it was acknowledged that the technique was performed by a few institutions within the Asian EUS group. Thus, formulation of a set of guidelines on the technique would be premature at this time. Rather, the group decided to formulate a positional statement on the technique to serve as a reference when performing the procedure for clinicians interested in undertaking the technique. The current set of statements are the first with specific focus on the technique published by any endoscopic society.

Management of PCNs has been the subject of much controversy. The principle of treating PCN is to prevent mortality associated with malignancy developing from a MPC. The main difficulty in recommending any treatment (surgical or endoscopic) for a PCN is that accurate diagnosis and risk stratification are frequently difficult. Further, there is a lack of consensus about risk of a MPC harboring malignancy. Thus, several authors suggested that routine clinical use of EUS-guided pancreatic cyst ablation may be premature $[60,61]$. They have also been critical about inclusion in some published studies on cyst ablation of patients with likely benign pancreatic cysts (e.g. serous cystadenomas) which carry little risk of malignant progression, possibly subjecting the patients to unnecessary risk of pancreatitis.

Another recurring criticism of EUS-guided pancreatic cyst ablation is that response to treatment is based on radiological measurement of cyst size which is, in effect, a surrogate out- come for response to treatment and cannot lead to presumption that complete epithelial ablation of the cyst will have reliably occurred. Furthermore, pancreatic ductal adenocarcinoma may still develop in the field defect of a susceptible pancreas and continued long-term surveillance is still required in patients that had IPMN with high-risk stigmata [13]. In that regard, a recent study of long-term outcomes after pancreatic cyst ablation has shown excellent long-term resolution rates of $98 \%$ at 6 years for patients who met the definition of complete ablation after treatment [13]. Furthermore, other treatment options (mainly a morbid surgery) also require long-term follow-up surveillance as well, and the need for post-treatment surveillance does not represent a requirement unique to ablation.

In the current statement, a comprehensive review of various aspects of the technique was performed. We suggest that institutions embarking on the procedure do so under a research protocol. We also encourage these institutions to include in such research protocol technologies that could improve diagnosis of pancreatic cysts. Use of NCLE, through-the-needle biopsy forceps, fiber optic visualization or DNA analysis appear to be promising technologies that could further improve diagnosis. The panel acknowledges the fact that when a specific diagnosis of cyst type can be made confidently, including risk stratification, treatment can then be more effectively allocated based on stratification of risk of malignancy. EUS-guided treatment may then gain more acceptance as a treatment option in these patients. Future studies should also address important issues that were raised previously on the exact effect of the ablating agent on the cyst epithelium and whether malignancy can be reliably prevented using large trials of cyst ablation.

\section{Conclusion}

In conclusion, the current set of statements on EUS-guided pancreatic cyst ablation are the first published by any endoscopic society. Clinicians interested in undertaking the technique should refer to these statements and future studies should address important issues raised in the document.

\section{Competing interests}

Prof. Teoh is a consultant for Boston Scientific, Cook, Taewoong and Microtech Medical Corporations.

\section{References}

[1] Tanaka M, Fernandez-del Castillo C, Adsay V et al. International consensus guidelines 2012 for the management of IPMN and MCN of the pancreas. Pancreatology 2012; 12: 183-197

[2] European Study Group on Cystic Tumours of the Pancreas. European evidence-based guidelines on pancreatic cystic neoplasms. Gut 2018; 67: $789-804$

[3] Scheiman JM, Hwang JH, Moayyedi P. American Gastroenterological Association technical review on the diagnosis and management of 
asymptomatic neoplastic pancreatic cysts. Gastroenterology 2015; 148: $824-848$ e822

[4] Guyatt GH, Oxman AD, Vist GE et al. GRADE: an emerging consensus on rating quality of evidence and strength of recommendations. BM] 2008; 336: $924-926$

[5] Guyatt GH, Oxman AD, Schunemann HJ et al. GRADE guidelines: a new series of articles in the Journal of Clinical Epidemiology. J Clin Epidemiol 2011; 64: 380-382

[6] Oh HC, Brugge WR. EUS-guided pancreatic cyst ablation: a critical review (with video). Gastrointest Endosc 2013; 77: 526- 533

[7] Moyer MT, Sharzehi S, Mathew A et al. The safety and efficacy of an alcohol-free pancreatic cyst ablation protocol. Gastroenterology 2017; 153: 1295-1303

[8] Oh HC, Seo DW, Song T] et al. Endoscopic ultrasonography-guided ethanol lavage with paclitaxel injection treats patients with pancreatic cysts. Gastroenterology 2011; 140: $172-179$

[9] Dewitt J, McGreevy K, Schmidt CM et al. EUS-guided ethanol versus saline solution lavage for pancreatic cysts: a randomized, doubleblind study. Gastrointest Endosc 2009; 70: 710-723

[10] Dewitt JM, Al-Haddad M, Sherman S et al. Alterations in cyst fluid genetics following endoscopic ultrasound-guided pancreatic cyst ablation with ethanol and paclitaxel. Endoscopy 2014; 46: 457-464

[11] Moyer MT, Dye CE, Sharzehi $S$ et al. Is alcohol required for effective pancreatic cyst ablation? The prospective randomized CHARM trial pilot study Endosc Int Ppen 2016; 4: E603 - E607

[12] Choi JH, Seo DW, Song TJ et al. Long-term outcomes after endoscopic ultrasound-guided ablation of pancreatic cysts. Endoscopy 2017; 49: $866-873$

[13] Gan SI, Thompson CC, Lauwers GY et al. Ethanol lavage of pancreatic cystic lesions: initial pilot study. Gastrointest Endosc 2005; 61: $746-$ 752

[14] Oh HC, Seo DW, Lee TY et al. New treatment for cystic tumors of the pancreas: EUS-guided ethanol lavage with paclitaxel injection. Gastrointest Endosc 2008; 67: 636-642

[15] Oh HC, Seo DW, Kim SC et al. Septated cystic tumors of the pancreas: is it possible to treat them by endoscopic ultrasonography-guided intervention? Scand J Gastroenterol 2009; 44: 242-247

[16] Dimaio C], dewitt JM, Brugge WR. Ablation of pancreatic cystic lesions: the use of multiple endoscopic ultrasound-guided ethanol lavage sessions. Pancreas 2011; 40: 664-668

[17] Park JK, Song BJ, Ryu JK et al. Clinical outcomes of endoscopic ultrasonography-guided pancreatic cyst ablation. Pancreas 2016; 45: 889-894

[18] Sainani NI, Saokar A, Deshpande V et al. Comparative performance of MDCT and MRI with MR cholangiopancreatography in characterizing small pancreatic cysts. AJR Am J Roentgenol 2009; 193: 722 - 731

[19] Sahani DV, Kambadakone A, Macari M et al. Diagnosis and management of cystic pancreatic lesions. AJR Am J Roentgenol 2013; 200: $343-354$

[20] Waters JA, Schmidt CM, Pinchot JW et al. CT vs MRCP: optimal classification of IPMN type and extent. J Gastrointest Surg 2008; 12: 101 109

[21] Pilleul F, Rochette A, Partensky C et al. Preoperative evaluation of intraductal papillary mucinous tumors performed by pancreatic magnetic resonance imaging and correlated with surgical and histopathologic findings. J Magn Reson Imaging 2005; 21: 237-244

[22] de Jong K, van Hooft JE, Nio CY et al. Accuracy of preoperative workup in a prospective series of surgically resected cystic pancreatic lesions. Scand J Gastroenterol 2012; 47: 1056-1063

[23] Ardengh JC, Lopes CV, de Lima-Filho ER et al. Impact of endoscopic ultrasound-guided fine-needle aspiration on incidental pancreatic cysts. A prospective study. Scand J Gastroenterol 2014; 49: 114-120
[24] Brugge WR, Lewandrowski K, Lee-Lewandrowski E et al. Diagnosis of pancreatic cystic neoplasms: a report of the cooperative pancreatic cyst study. Gastroenterology 2004; 126: 1330 - 1336

[25] Cizginer S, Turner BG, Bilge AR et al. Cyst fluid carcinoembryonic antigen is an accurate diagnostic marker of pancreatic mucinous cysts. Pancreas 2011; 40: $1024-1028$

[26] Koito K, Namieno T, Nagakawa T et al. Solitary cystic tumor of the pancreas: EUS-pathologic correlation. Gastrointest Endosc 1997; 45: $268-276$

[27] Morris-Stiff G, Lentz G, Chalikonda S et al. Pancreatic cyst aspiration analysis for cystic neoplasms: mucin or carcinoembryonic antigenwhich is better? Surgery 2010; 148: 638-644; discussion 644-635

[28] Al-Haddad M, dewitt J, Sherman S et al. Performance characteristics of molecular (DNA) analysis for the diagnosis of mucinous pancreatic cysts. Gastrointest Endosc 2014; 79: $79-87$

[29] Gaddam S, Ge PS, Keach JW et al. Suboptimal accuracy of carcinoembryonic antigen in differentiation of mucinous and nonmucinous pancreatic cysts: results of a large multicenter study. Gastrointest Endosc 2015; 82: 1060 - 1069

[30] Kadayifci A, Al-Haddad M, Atar M et al. The value of KRAS mutation testing with CEA for the diagnosis of pancreatic mucinous cysts. Endosc Int Open 2016; 4: E391-396

[31] Khalid A, Zahid M, Finkelstein SD et al. Pancreatic cyst fluid DNA analysis in evaluating pancreatic cysts: a report of the PANDA study. Gastrointest Endosc 2009; 69: 1095-1102

[32] Winner M, Sethi A, Poneros JM et al. The role of molecular analysis in the diagnosis and surveillance of pancreatic cystic neoplasms. J Pancreas 2015; 16: $143-149$

[33] Konda VJ, Meining A, Jamil LH et al. A pilot study of in vivo identification of pancreatic cystic neoplasms with needle-based confocal laser endomicroscopy under endosonographic guidance. Endoscopy 2013; 45: $1006-1013$

[34] Napoleon B, Lemaistre Al, Pujol B et al. In vivo characterization of pancreatic cystic lesions by needle-based confocal laser endomicroscopy (ncle): proposition of a comprehensive ncle classification confirmed by an external retrospective evaluation. Surg Endosc 2016; 30: $2603-2612$

[35] Napoleon B, Lemaistre Al, Pujol B et al. A novel approach to the diagnosis of pancreatic serous cystadenoma: needle-based confocal laser endomicroscopy. Endoscopy 2015; 47: 26-32

[36] Nakai Y, Iwashita T, Park DH et al. Diagnosis of pancreatic cysts: EUSguided, through-the-needle confocal laser-induced endomicroscopy and cystoscopy trial: DETECT study. Gastrointest Endosc 2015; 81: $1204-1214$

[37] Krishna SG, Swanson B, Hart PA et al. Validation of diagnostic characteristics of needle based confocal laser endomicroscopy in differentiation of pancreatic cystic lesions. Endosc Int Open 2016; 4: E1124E1135

[38] Kadayifci A, Atar M, Basar O et al. Needle-Based confocal laser endomicroscopy for evaluation of cystic neoplasms of the pancreas. Dig Dis Sci 2017; 62: 1346 - 1353

[39] Nakai Y, Isayama H, Chang KJ et al. A pilot study of EUS-guided through-the-needle forceps biopsy (with video). Gastrointest Endosc 2016; 84: $158-162$

[40] Mittal C, Obuch JC, Hammad H et al. Technical feasibility, diagnostic yield, and safety of microforceps biopsies during EUS evaluation of pancreatic cystic lesions (with video). Gastrointest Endosc 2018; 87: $1263-1269$

[41] Chai N, Feng J, Guo Y et al. Preliminary study of single-operator cholangioscopy for diagnosing pancreatic cystic lesions. Gastrointest Endosc 2017; 86: $208-218$

[42] Zhu H, Jiang F, Zhu J et al. Assessment of morbidity and mortality associated with endoscopic ultrasound-guided fine-needle aspiration 
for pancreatic cystic lesions: A systematic review and meta-analysis. Dig Endosc 2017; 29: 667-675

[43] Guarner-Argente C, Shah P, Buchner A et al. Use of antimicrobials for EUS-guided FNA of pancreatic cysts: a retrospective, comparative analysis. Gastrointest Endosc 2011; 74: 81-86

[44] Klein A, Qi R, Nagubandi S et al. Single-dose intra-procedural ceftriaxone during endoscopic ultrasound fine-needle aspiration of pancreatic cysts is safe and effective: results from a single tertiary center. Ann Gastroenterol 2017; 30: 237-241

[45] Marinos E, Lee $S$, Jones B et al. Outcomes of single-dose peri-procedural antibiotic prophylaxis for endoscopic ultrasound-guided fineneedle aspiration of pancreatic cystic lesions. United European Gastroenterol J 2014; 2: $391-396$

[46] Polkowski M, Jenssen C, Kaye P et al. Technical aspects of endoscopic ultrasound (EUS)-guided sampling in gastroenterology: European Society of Gastrointestinal Endoscopy (ESGE) Technical Guideline March 2017. Endoscopy 2017; 49: 989-1006

[47] Varadarajulu S, Bang JY, Hebert-Magee S. Assessment of the technical performance of the flexible 19-gauge EUS-FNA needle. Gastrointest Endosc 2012; 76: $336-343$

[48] Cho MK, Choi JH, Seo DW. Endoscopic ultrasound-guided ablation therapy for pancreatic cysts. Endosc Ultrasound 2015; 4: 293-298

[49] Gelczer RK, Charboneau JW, Hussain S et al. Complications of percutaneous ethanol ablation. J Ultrasound Med 1998; 17: 531 - 533

[50] Gomez V, Takahashi N, Levy M] et al. EUS-guided ethanol lavage does not reliably ablate pancreatic cystic neoplasms (with video). Gastrointest Endosc 2016; 83: $914-920$

[51] Linghu E, Du C, Chai N et al. A prospective study on the safety and effectiveness of using lauromacrogol for ablation of pancreatic cystic neoplasms with the aid of EUS. Gastrointest Endosc 2017; 86: 872 880
[52] Ebrahimi SRS, Enamzadeh E, Babaei H. An evidence-based review of off-label uses of polidocanol. Curr Clin Pharmacol 2017; 12: 223-230

[53] Kim KH, mcgreevy K, La Fortune K et al. Sonographic and cyst fluid cytologic changes after EUS-guided pancreatic cyst ablation. Gastrointest Endosc 2017; 85: $1233-1242$

[54] Dewitt J, dimaio C], Brugge WR. Long-term follow-up of pancreatic cysts that resolve radiologically after EUS-guided ethanol ablation. Gastrointest Endosc 2010; 72: 862 - 866

[55] Oh HC, Seo DW, Kim SH et al. Systemic effect of endoscopic ultrasonography-guided pancreatic cyst ablation with ethanol and paclitaxel. Dig Dis Sci 2014; 59: 1573 - 1577

[56] Committee AT, dimaio C], Mishra G et al. EUS core curriculum. Gastrointest Endosc 2012; 76: 476-481

[57] Eisen GM, Dominitz JA, Faigel DO et al. Guidelines for credentialing and granting privileges for endoscopic ultrasound. Gastrointest Endosc 2001; 54: 811-814

[58] Teoh AYB, Dhir V, Kida M et al. Consensus guidelines on the optimal management in interventional EUS procedures: results from the Asian EUS group RAND/UCLA expert panel. Gut 2018; 67: 1209-1228

[59] Yachimski P, Varadarajulu S. Endoscopic ultrasound-guided pancreatic cyst ablation: more peril than promise? Gastroenterology 2017; 153: $1183-1185$

[60] Fernandez-Del Castillo C. EUS treatment of pancreatic cysts: let's keep the alcohol (and the chemotherapy) locked in the cupboard. Gastroenterology 2011; 140: $2144-2145$

[61] Crippa S, Pezzilli R, Bissolati M et al. Active surveillance beyond 5 years is required for presumed branch-duct intraductal papillary mucinous neoplasms undergoing non-operative management. Am J Gastroenterol 2017; 112: $1153-1161$ 